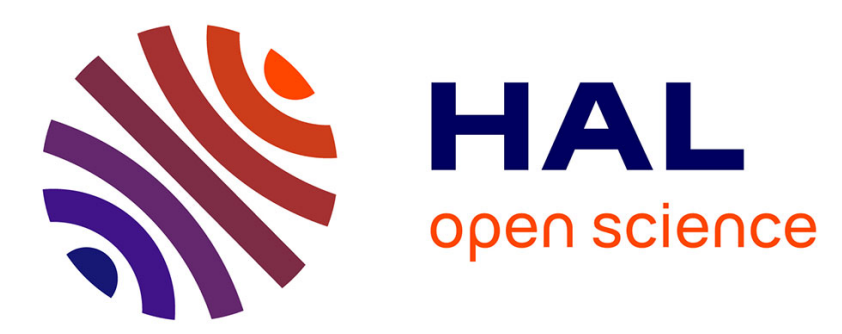

\title{
A Method Towards Modelling and Analysis of Semantically-Enriched Reconfigurable Manufacturing Systems
}

Damiano Nunzio Arena, Dimitris Kiritsis

\section{- To cite this version:}

Damiano Nunzio Arena, Dimitris Kiritsis. A Method Towards Modelling and Analysis of SemanticallyEnriched Reconfigurable Manufacturing Systems. IFIP International Conference on Advances in Production Management Systems (APMS), Sep 2016, Iguassu Falls, Brazil. pp.45-52, 10.1007/978-3-31951133-7_6. hal-01615759

\author{
HAL Id: hal-01615759 \\ https://hal.inria.fr/hal-01615759
}

Submitted on 12 Oct 2017

HAL is a multi-disciplinary open access archive for the deposit and dissemination of scientific research documents, whether they are published or not. The documents may come from teaching and research institutions in France or abroad, or from public or private research centers.
L'archive ouverte pluridisciplinaire HAL, est destinée au dépôt et à la diffusion de documents scientifiques de niveau recherche, publiés ou non, émanant des établissements d'enseignement et de recherche français ou étrangers, des laboratoires publics ou privés.

\section{(c)(1)}

Distributed under a Creative Commons Attribution| 4.0 International License 


\title{
A Method Towards Modelling and Analysis of Semantically-enriched Reconfigurable Manufacturing Systems
}

\author{
Damiano Nunzio Arena and Dimitris Kiritsis \\ École Politechnique Fédérale de Lausanne, Lausanne, Switzerland \\ \{damiano.arena, dimitris.kiritsis\}@epfl.ch
}

\begin{abstract}
Modelling and simulation are two relevant facets for thorough and effective analysis of industrial systems that nowadays have to cope with the evergrowing complexity of the industrial processes and the need of modelling flexibility and knowledge sharing. For all these reasons, the following work seeks to explore and combine together different methodologies by exploiting their best features. In particular, the current research aims to combine semantic technologies, such as ontologies, and high-level Petri nets to revamp the actual assembly systems. Thus, key research concepts are presented, explaining such potential integration and providing a short example of the dynamic configuration of an assembly system within a semantically enriched modelling environment.
\end{abstract}

Keywords: Reconfigurable manufacturing systems · Colored petri net - Ontologies

\section{Problem Statement}

In today's manufacturing industry, staying in business is a life-and-death issue for many manufacturing companies. It is well-known that the one thing most surviving or winning manufacturing companies have in common is continuous improvement and adaptation of their manufacturing systems. During the last few decades, these have thoroughly evolved, from low volume, high variety jobshop production systems to more robust mid-volume and variety flexible manufacturing systems. Nonetheless, manufacturing systems still suffered from low responsiveness and large capital investment until the introduction of reconfigurable manufacturing systems. Reconfigurability can be defined as the ability to repeatedly change capacity and functionality in a cost-efficient way, in order to meet different demand situations in terms of variation in volume as well as in product characteristics [1]. This ability can be achieved at different enterprise levels, e.g. network, factory, segment, system, cell, workstation [2].

Though there is a substantial amount of research work available in the domain of reconfigurable systems, especially at system level [3], systems with full level of reconfigurability are still non-existent [4]. In particular, in the domain of developing Reconfigurable Manufacturing Systems (RMS), just limited research 
that incorporates its true dynamic, rapid nature and accurate decision making in complex systems is available.

Towards development of Reconfigurable Manufacturing Systems, several promising models have been proposed in the past two decades $[5,6,7,8]$. However, these models are only limited to control, physical and structural aspects that would support reconfiguration but lacked a rapid reconfigurability and decision making capabilities.

To summarize, our effort in this work focuses on the definition of a semanticenriched modelling environment for Reconfigurable Manufacturing Systems taking full advantage of the dynamic properties of ontologies and Petri nets.

\section{Proposed Approach}

The objective of this research is to investigate and support the re-configurability of manufacturing systems by applying CPN modelling language and Knowledge Engineering (KE) methodologies, such as Ontologies. The rationale of this work is two-fold:

- Semantic extraction and modelling of Reconfigurable Manufacturing Systems.

- Integration of the aforementioned enabling technologies to support the dynamic design of Reconfigurable Manufacturing Systems.

The key feature of this approach resides with the integration of Semantic Techniques and Colored Petri Nets. This potential integration seeks to bridge the lack of interoperability between such methodologies by creating a Semantically Enriched Environment where a RMS can be (dynamically) instantiated.

CPNs are proven to be suitable for modelling the system structure and behavior, therefore, RMS concepts are mapped into CPN ones, and then transformed into CPN-oriented elements. The resulting CPN model can be, therefore, verified and simulated in order to explore and perform either quantitative or qualitative analysis of the system [16]. In particular, qualitative analysis searches for structural properties [17], such as:

- absence of deadlocks

- absence of overflows

- presence of certain mutual exclusions (in case of resource sharing)

Quantitative analysis, instead, looks for performance properties such as:

- throughput, average completion times

- average queue lengths

- utilization rates

The simulation outcomes can be, hence, reasoned in order to feedback the system and achieve continuous re-adaptation and improvement. Figure 1 shows the proposed (closed-loop) architecture together with an overview of the main system elements: 


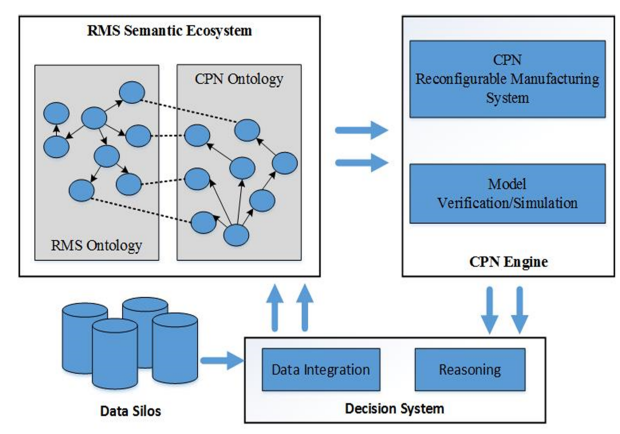

Fig. 1. System Architecture

- Data Silos, manufacturing/assembly data that are a vital element for the RMS itself, which are either structured or unstructured;

- DS, decision system based on semantic technologies, that aims to provide data integration and reasoning features;

- Semantic Ecosystem, where domain-specific ontology elements are related to one another to enable CPN concepts inferring from RAS ones;

- CPN engine to perform the above-mentioned assessments.

A Reconfigurable Manufacturing System poses itself a modelling challenge because of its dynamic nature. On the other hand, Petri Net formalism, and in particular CPN, has a general-purpose nature and it is based on strong math foundations, which results very suitable for both modelling and analysis phases of reconfigurable systems.

\section{Method Conceptualization}

The backbone of this solution is represented by the semantic-enriched environment through which all the domain specific concepts are outlined and related each other. Particular emphasis has to be given to the non-trivial semantics of the selected modelling language (CPN), which extends the simple PN formalism by introducing some enriched features. In fact, the so-called CPN Ontology (see Figure 2) should consists of basic PN concepts (place, transition, arc, and token) plus high-level ones (see table 1).

The RMS Ontology, should consists, instead, of domain specific concepts, such as Equipment, Components, Worker roles, Work Station (see Figure 3). However, some details about this ontology models have been omitted. As mentioned earlier, ontologies themselves do not provide simulable models. The introduction of PN-based concepts, hence, aims to bridge this lack of simulation through the translation of RMS elements into CPN ones. In this regards, Zhou et.al [18] suggest an interpretation of the simple PN elments such as Places, Transitions and directed Arcs (see Table 2), which can be, therefore, inferred 
Table 1. CPN ontology classes and relations

\begin{tabular}{|l|l|l|l|}
\hline \multirow{2}{*}{\multicolumn{1}{c|}{ Class }} & \multirow{2}{*}{ subClassOf } & \multicolumn{2}{c|}{ Class Property } \\
\cline { 3 - 4 } & & \multicolumn{1}{c|}{ Name } & \multicolumn{1}{c|}{ Range } \\
\hline CPN_Element & Thing & - & - \\
\hline Place & CPN_Element & hasTokens & Token \\
\hline Transition & CPN_Element & hasTInscription & Inscription \\
\hline Arc & CPN_Element & hasAInscription & Inscription \\
\hline PTArc & Arc & connectsTransitionTo & Transition \\
\hline TPArc & Arc & connectsPlaceTo & Place \\
\hline Token & CPN_Element & hasInfo & TokenInfo \\
\hline TokenInfo & Token & - & - \\
\hline Inscription & CPN_Element & - & - \\
\hline A_Inscription & Inscription & definesFlowRuleOn & Arc \\
\hline T_Inscription & Inscription & definesExecutionRuleOn & Transition \\
\hline
\end{tabular}

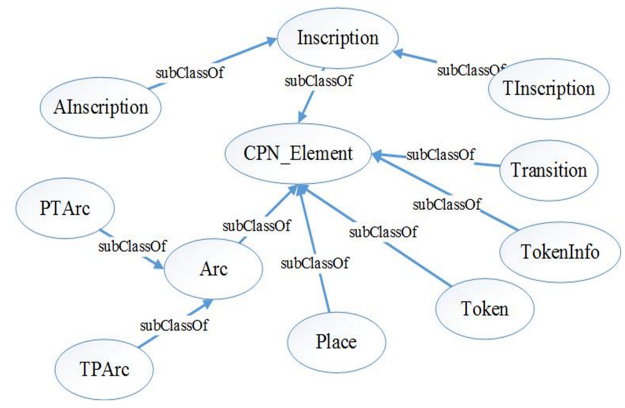

Fig. 2. CPN Ontology

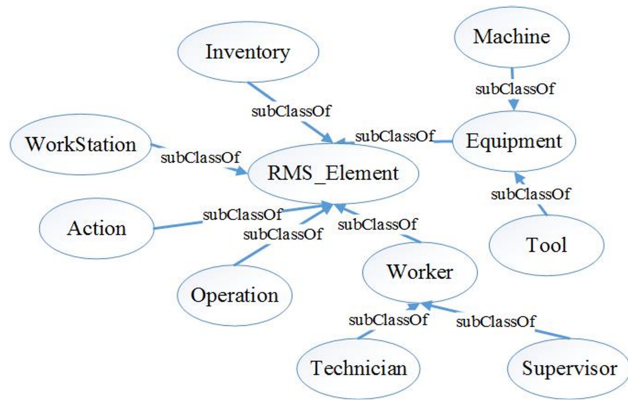

Fig. 3. RMS Ontology

through the semantic models. The proposed approach, in fact, aims to set inference rules to automatically perform the aforementioned concepts mapping and, then, provide a PN-based semantic-enriched description of the re-configurable assembly system. For example, using a human readable syntax, we can set the following rule: 


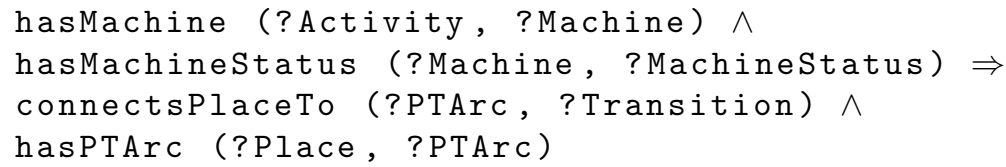

Table 2. Interpretation of the PN elements

\begin{tabular}{|l|l|}
\hline PN Elements & Interpretation \\
\hline Places & Resource status, operations and conditions \\
\hline Transitions & Operations, processes, activities and events \\
\hline Directed Arcs & $\begin{array}{l}\text { Material, resource, information, and } \\
\text { control flow direction }\end{array}$ \\
\hline
\end{tabular}

This is valid according to the assumption that an Activity is intepreted as a Transition and a MachineStatus as a Place. These can be then instantiated as shown in Figure 4.

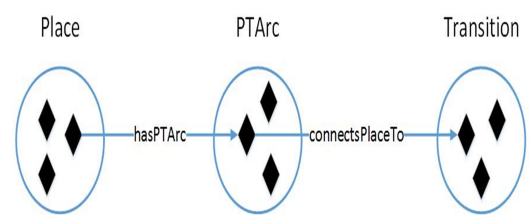

Fig. 4. PlacePTArcTransition inference-based instantiation

That said, the exploration of the system behavior through the Decision System aims at achieving continuous re-adaptation of the model according to specific goals. Let us consider the RMS as described in the PN model below (see Figure. 5). The system might be influenced by different conditions, for example:

- The sequence can be optimized (respecting the technological specifications)

- The work load of the assigned operator should be modified by splitting the execution of those steps among more operator, e.g. increasing the efficiency of the process.

- The expected output should be adapted to respond new customer requirements

Thus, starting from the initial configuration, the system will require some adjustments and consequence re-assessment. For instance, a small portion of the model will be reconfigured (see Figure 6) according to the new requirements revealed by the DS. In fact, once the system receives an input from the DS regarding the need of reconfiguring the system, the new Manufacturing System can be instantiated within the semantic framework, then, translated into Petri 


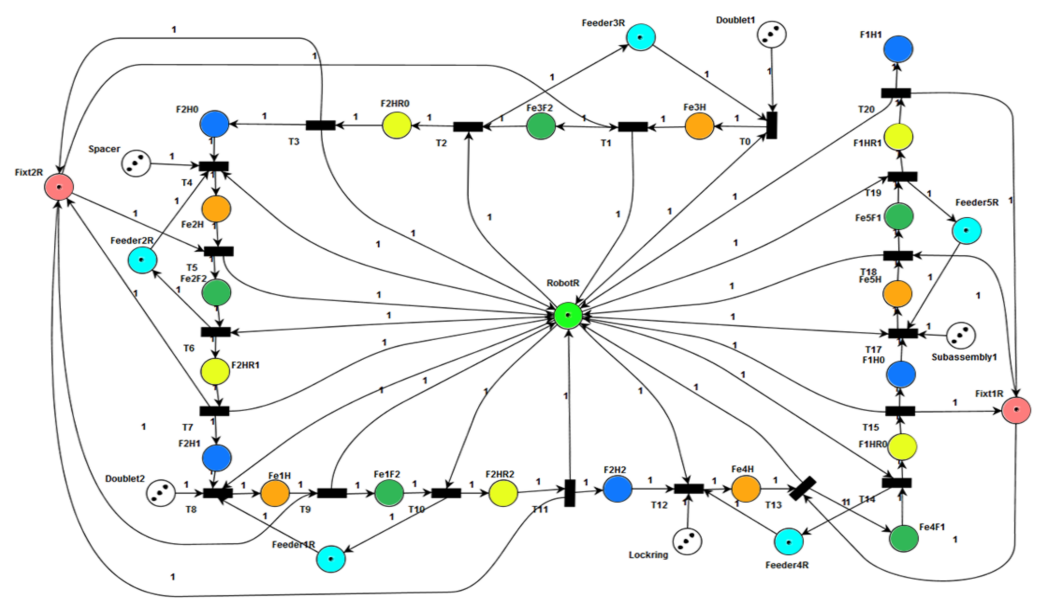

Fig. 5. RMS initial configuration

Net entities and finally transformed into a new CPN-based model that can be further verified and analyzed.

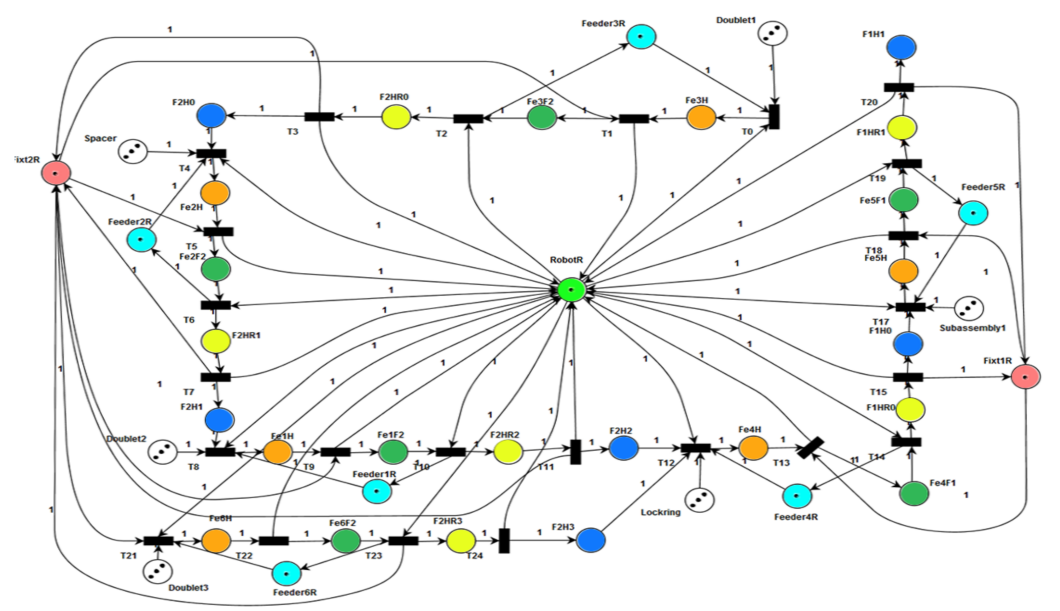

Fig. 6. Reconfigured Manufacturing System

\section{Conclusions}

In the current research we focus on the conceptualization of a modelling framework for Reconfigurable Manufacturing Systems based on Colored Petri Nets and 
Knowledge Engineering technologies, such as Ontologies. The scope of the presented work is to provide an overview of the key concepts, modelling issues and potential solutions together with a short example of a reconfigurable assembly system. Petri nets are used to model the Manufacturing System while ontologies are exploited to achieve system interoperability, integration and reusability through semantics. However, the work is still at an early stage and requires some effort in terms of both analysis and implementation in order to explore more critical design facets and pinpoint eventual drawbacks, which might prevent the full interoperability among the system elements. In particular, future work will necessitate the formal assessment of design and deployment requirements (e.g. semantics integration, verification and simulation metrics), the selection of a suitable development environment, and the instantiation of a real case scenario. In this regard, the presented modelling approach has been applied to RMS example but it will be re-used and further tested in the context of SatisFactory European research project in order to support the analysis and design of dynamically evolving shop floor operations.

\section{References}

1. Mehrabi, M.G., Ulsoy, A.G., Koren, Y.: Reconfigurable Manufacturing Systems: Key to Future Manufacturing. Journal of Intelligent Manufacturing 11(4), 403-419 (2000)

2. Wiendahl, H.P., ElMaraghy, H., Nyhuis, P., Zh, M., Wiendahl, H.H., Duffie, N., Brieke, M.: Changeable Manufacturing - Classification, Design and Operation. CIRP Annals - Manufacturing Technology 56(2), 783-809 (2007)

3. Andersen, A.L., Brunoe, T.D., Nielsen, K.: Reconfigurable Manufacturing on Multiple Levels: Literature Review and Research Directions. pp. 266-273 (2015)

4. ElMaraghy, H.A.: Flexible and Reconfigurable Manufacturing Systems Paradigms. International Journal of Flexible Manufacturing Systems 17(4), 261-276 (2005)

5. Rakesh, K., Jain, P., Mehta, N.: A Framework for Simultaneous Recognition of Part Families and Operation Groups for Driving a Reconfigurable Manufacturing System. Advances in Production Engineering \\& Management Journal 5(1), 45-58 (2010)

6. Nourelfath, M., Aitkadi, D., Isaac Soro, W.: Availability Modeling and Optimization of Reconfigurable Manufacturing systems. Journal of Quality in Maintenance Engineering 9(3), 284-302 (2003)

7. da Silva, R.M., Bentez-Pina, I.F., Blos, M.F., Filho, D.J.S., Miyagi, P.E.: Modeling of Reconfigurable Distributed Manufacturing Control Systems. IFACPapersOnLine 48(3), 1284-1289 (2015)

8. Lohse, N., Ratchev, S., Valtchanov, G.: Towards WebEnabled Design of Modular Assembly Systems. Assembly Automation 24(3), 270-279 (2004)

9. Shah, S.A., Bohez, E.L., Pisuchpen, R.: New Modeling and Performance Evaluation of Tool Sharing Control in FMS Using Colored Petri Nets. Assembly Automation 31(2), 137-152 (2011)

10. Yu, J., Yin, Y., Sheng, X., Chen, Z.: Modelling Strategies for Reconfigurable Assembly Systems. Assembly Automation 23(3), 266-272 (2003)

11. Kuo, C.H., Huang, H.P., Wei, K.C., Tang, S.S.H.: System Modeling and Real-Time Simulator for Highly Model-Mixed Assembly Systems. Journal of Manufacturing Science and Engineering 121(2), 282 (1999) 
12. Jensen, K.: Coloured Petri Nets: Basic Concepts, Analysis Methods and Practical Use., vol. 1. Springer Science \& Business Media, Berlin, Heidelberg (2013)

13. Zhang, L.L.: Process Platform-based Production Configuration for Mass Customization. (2007)

14. Vidal, J.C., Lama, M., Bugarn, A.: OPENET: Ontology-based Engine for Highlevel Petri Nets. Expert Systems with Applications 37(9), 6493-6509 (2010)

15. Zhang, F., Ma, Z.M., Ribaric, S.: Representation of Petri Net With OWL DL Ontology. pp. 1396-1400. IEEE (2011)

16. Tysz, F., Kahraman, C.: Modeling a Flexible Manufacturing Cell Using Stochastic Petri Nets With Fuzzy Parameters. Expert Systems with Applications 37(5), 39103920 (2010)

17. Kahraman, C., Tysz, F.: Manufacturing System Modeling Using Petri Nets. In: Kahraman, C. (ed.) Production Engineering and Management under Fuzziness, pp. 95-124. Springer Berlin Heidelberg, Berlin, Heidelberg (2010) 